\title{
CÂNCER DO COLO DO ÚTERO: ANÁLISE DOS CONTRASTES REGIONAIS NA MORTALIDADE
}

\author{
Jefferson Marlon de Medeiros Pereira Maciel ${ }^{l}$; Raquel Carlos de Brito ${ }^{l}$; Leandro Januário de Lima ${ }^{l}$; \\ Ana Beatriz de Melo Alves ${ }^{2}$; Andreza Guedes Barbosa Ramos ${ }^{3}$
}

Introdução: O Câncer do Colo do Útero (CCU) é uma causa de morte evitável quando diagnosticado e tratado precocemente ${ }^{1}$, mas apesar disso, no cenário mundial, o CCU representa, entre as mulheres, a segunda neoplasia com maior incidência e uma das causas de óbito mais frequentes em países de baixa renda.A compreensão dos determinantes sociais, individuais e regionais é de suma importância para identificação de grupos populacionais de maior risco e elaboração de estratégias que tornem equânime o acesso à saúde. Objetivos: Relacionar os diferentes índices de mortalidade por CCU com as particularidades de cada região brasileira. Método: Trata-se de uma revisão sistemática sem metanálise seguindo a estrutura descrita por Egger e Smith. Realizou-se uma busca nas bases de dados SciELO, LILACS, MEDLINE, com os descritores "Neoplasias do Colo do Útero", "Brasil" e "Mortalidade". Os critérios de inclusão estabelecidos foram estudos primários e secundários, desenvolvidos no Brasil, publicados a partir de 2000, e em idioma português. Resultados: A amostra foi composta por 08 estudos primários, sendo 04 publicados na Revista de Saúde Pública e todos utilizando dados dos Sistemas de Informação em Saúde. As análises de tendência temporal da mortalidade indicam a existência de movimentos diferenciados do CCU no país, reflexo indireto da incidência e direto dos indicadores socioeconômicos das mulheres, do acesso aos serviços de saúde, da qualidade da assistência prestada e da veracidade dos registros. É nítida a queda dos óbitos em mulheres residentes das regiões Sudeste, Sul e Centro-Oeste, enquanto nas regiões Norte e Nordeste, com exceção das capitais, há elevação. Mulher com baixa renda per capita, baixa escolaridade, sem plano de saúde privado, residente em zona rural ou distante do centro urbano, constitui o grupo com menor chance de realizar o rastreio do CCU, não detectando-o precocemente e dificultando o prognóstico. Conclusão: As metas de diagnóstico precoce e queda na taxa de mortalidade não alcançadas se refletem em necessidades médicas não atendidas perante os estágios de desenvolvimento do país e de suas particularidades territoriais, socioculturais e econômicas. Portanto, enfatiza-se a necessidade de maiores intervenções que deem atenção especial aos grupos sob maior risco, e para que elas sejam efetivas devem incluir medidas que promovam maior equidade no acesso, com garantia de tratamento adequado e seguimento.

Palavras-chave: Neoplasia do Colo do Útero; Brasil; Mortalidade.

\footnotetext{
${ }^{1}$ Acadêmicos de Medicina da Universidade Federal de Campina Grande, campus Cajazeiras/PB;

2 Interna de Medicina da Faculdade Estácio de Medicina de Juazeiro do Norte;

${ }^{3}$ Doutoranda pela Universidade Regional do Cariri e Professora Assistente de Medicina da Universidade Federal de Campina Grande, campus Cajazeiras/PB;

Autor correspondente: jeffersonmmpmaciel@hotmail.com.
}

23 Id on Line Rev. Mult. Psic. V.12, N. 40. 2018 - ISSN 1981-1179 EDIÇÃO ESPECIAL: I CURSO DE ONCOLOGIA DO CARIRI / II JORNADA DE PESQUISA QUANTI-QUALITATIVA EM ONCOLOGIA. JUAZEIRO DO NORTE, 05 A 10 DE MARÇO DE 2018. Edição eletrônica em http://idonline.emnuvens.com.br/id 